\title{
BENTUK DAN FUNGSI TEKS MANTRA
}

\section{THE FORM AND FUNCTION OF MANTRA TEXT}

\author{
Mulyanto, Edi Suwatno \\ Balai Bahasa Daerah Istimewa Yogyakarta \\ Jalan I D ewa Nyoman O ka 34, Yogyakarta \\ Mulyanto.ms@gmail.com
}

\begin{abstract}
A bstract
Mantra has a speial formof langragethat is considared can connet peeplewith things that arend concte Thespdl langragehas poticdenents surhashymeandrhythm andisconsidzedtocontain spematural powes Thedisindive langrage of themantra needstobestudiedin tems of formandfuntion tobeknounby thepeeplesothat theywill not havewrongassmption on mantra. Data aredtainedfromvarias oral literary texts This sudy uses thethery of structuralismof Jean Peagr. Theresults show that themantra language can bein theformof pantum, podry, lyic prose repetition of saund, anddhant. Mantra hasfindionsfor kindip treatment, pest eadication, immunity, games health love(compassin), andliveihood
\end{abstract}

Keywords: spell form, potry, occult, function

\begin{abstract}
Abstrak
Mantra memiliki bentuk bahasa khusus yang dianggap dapat menghubungkan manusia dengan hal yang tidak konkret. Bahasa mantra berunsur puisi, seperti rima dan irama, dan dianggap mengandung kekuatan gaib. Bahasa yang khas pada mantra perlu dikaji bentuk dan fungsinya agar dapat diketahui oleh masyarakat sehingga mereka terhindar dari anggapan yang tidak benar terhadap mantra. D ata diperoleh dari berbagai teks sastra lisan. Penelitian ini menggunakan teori strukturalisme Jean Peager. Hasil penelitian menunjukkan bahwa bahasa mantra dapat berbentuk pantun, puisi, prosa lirik, pengulangan bunyi, dan kidung. Mantra memiliki fungsi untuk kekeluargaan, pengobatan, membasmi hama, kekebalan, permainan, kesehatan, cinta kasih (berkasih-kasihan), dan mata pencaharian.
\end{abstract}

Kata kunci: bentuk mantra, puisi, gaib, fungsi

\section{PENDAHULUAN}

Mantra digunakan dalam berbagai bahasa dan kesastraan daerah di seluruh Indonesia, seperti dalam bahasa Banjar, Jawa, Lampung, Minangkabau, Palembang, Sunda, dan sebagainya. Mantra merupakan perkataan atau ucapan yang memiliki kekuatan gaib, misalnya dapat menyembuhkan penyakit, mendatangkan kecelakaan, dan sebagainya; atau susunan kata berunsur puisi, (seperti rima, irama) yang dianggap mengandung kekuatan gaib, biasanya diucapkan oleh dukun atau pawang untuk menandingi kekuatan gaib yang lain (KBBI, 2014:
876). Mantra berhubungan dengan sikap religius manusia. Untuk memohon sesuatu kepada Tuhan diperlukan kata-kata pilihan yang berkekuatan gaib yang oleh penciptanya dipandang mempermudah hubungan dengan Tuhan.

Mantra bersifat sakral. O leh karena itu, mantra seringkali tidak boleh diucapkan oleh setiap (sembarang) orang. Biasanya hanya seorang pawang atau dukun yang berhak dan boleh mengucapkan mantra. Pengucapan mantra pun harus disertai dengan upacara ritual atau magis. D engan suasana yang ritual atau magis itulah mantra akan menimbulkan ke- 
kuatan gaib. Mantra tidak hanya terdapat di dalam buku-buku suci agama Hindu dan Budha, dalam lontar, benda tanah liat, dan dalam sastra Jawa Kuno (Zoetmuder,1983: 13), tetapi juga terdapat dalam sastra Melayu Lama. D alam membicarakan puisi kuna, Hooykas (1951: 20, 46-47) memasukkan pembicaraan mantra atau serapah. Mantra diucapkan oleh pawang dan digunakan pada saatsaat panen, menangkap ikan, berburu, mengumpulkan hasil hutan, dan digunakan untuk mengusir hantu-hantu jahat atau membujuk hantu-hantu yang baik.

Alisjahbana (1975:95) menggolongkan mantra ke dalam golongan bahasa berirama. Bahasa berirama ini termasuk jenis puisi lama. D alam bahasa berirama itu, irama bahasa sangat dipentingkan, terutama dalam mantra irama yang kuat dan teratur dengan maksud untuk berhubungan dengan kekuatan gaib. Mantra dibacakan (dilafalkan) oleh dukun sesuai dengan maksud dan tujuan yang ingin dicapai.

Di dalam mantra, sebuah kata tidak hanya mengantarkan pengertian tertentu (yang sesuai dengan kata itu), tetapi sekaligus mengantarkan pengertian dan keadaan yang lebih luas. Sering sebuah kata tertentu, selain mewakili pengertian tertentu, juga ada yang langsung mewakili "bendanya" atau "hal keadaannya" (Medan, 1975:21). Hal tersebut menunjukkan bahwa mantra hidup subur dalam kepercayaan animisme atau dengan totemisme. Namun, masuknya ajaran Islam berpengaruh dalam asimilasi budaya. Ajaran Islam memengaruhi semakin berkurangnya mantra-mantra jahat (hitam) karena mantra jenis itu dianggap tidak cocok. Sementara itu, mantra-mantra yang bertujuan baik tetap hidup dan dikaitkan dengan kepercayaan dan ajaran Islam.

Sebagai jenis sastra, mantra menjadi unik dan menarik sebagai bentuk puisi yang sangat ekspresif. Sebuah mantra tidak akan ada artinya apabila proses pemusatan dan pendalaman tidak mencapai titik maksimal. Hal inilah yang disebut di dalam mantra sebagai tingkat penyerahan diri kepada Tuhan, yang naik setingkat demi setingkat sehingga sampai ke tingkat keyakinan yang kuat atau "makrifat". Hal ini pula tampaknya yang menarik perhatian para penyair modern (seperti Sutardji Calzoum Bachri) untuk lebih banyak berorientasi terhadap puisi mantra.

Mantra merupakan salah satu jenis sastra lisan yang berkaitan dengan tradisi masyarakat daerah setempat. Sebagai sastra lisan, mantra merupakan salah satu bentuk kebudayaan daerah yang diwariskan sebagai tradisi lisan. O leh karena itu, perlu diusahakan penggalian, inventarisasi, dan dokumentasi yang cermat. Di samping itu, mantra masih difungsikan sebagai syair oleh para penyair modern yang berorientasi kepada mantra karena lebih cocok dan relevan dengan suasana yang diperlukan puisi modern.

Berdasarkan latar belakang permasalahan di atas, persoalan yang akan dibicarakan dalam tulisan ini dibatasi pada mantra berdasarkan bentuk dan fungsinya. Bentuk mantra di dalamnya sudah mencakupi isinya. D engan demikian, setiap bentuk mantra itu sekaligus di dalamnya adalah isi mantra itu sendiri dan masing-masing bentuk mantra mempunyai fungsi. Tujuan penelitian ini adalah untuk memperoleh deskripsi bentuk-bentuk/ isi dan fungsi mantra dalam masyarakat yang terdapat pada sastra lisan di daerah wilayah Indonesia

Mantra sebagai salah satu sastra lisan merupakan hasil kebudayaan dalam masyarakat tradisional yang isinya dapat disejajarkan dengan sastra tulis modern dan mantra merupakan salah satu sastra lisan yang diwariskan secara lisan, seperti pantun, nyanyian rakyat, dan cerita rakyat. Mantra sebagai salah satu jenis sastra lisan memiliki manfaat, yaitu sebagai dokumentasi dan sebagai sumber informasi yang luas dan sangat penting. Mantra yang tersebar di seluruh Indonesia itu bila isinya dipahami maknanya akan bermanfaat dan mampu 
menjadi sumbangan dalam mengukuhkan jati diri bangsa.

\section{METODE}

Metode yang digunakan dalam penelitian ini adalah metode deskriptif analisis dan studi pustaka. D eskripsi dilakukan dengan analisis konsepkonsep yang terdapat dalam teori yang diperoleh dari studi pustaka, selanjutnya dilakukan identifikasi berdasarkan bentuk/ isi dan fungsi mantra. Populasi dalam penelitian ini ialah wilayah persebaran mantra di Indonesia atau sejumlah wilayah, seperti Sastra lisan Sunda, Jawa Barat, Sastra Lisan Jawa, Sastra Lisan Sumatera Barat, Sastra Lisan Kalimantan, dan sebagainya. Sampel dalam penelitian bila ditilik dari letak geografis adalah sebagai berikut. Pulau Sumatera, seperti SastraLisanMinang kabau (1981); Sastra Lisan Sumende Sumsd (2000); SastraLisan Ogan(1994); SastraLisan Bahasa Mdayu Belitung (1992), Sastra Lisan Musi (1991); Pulau Jawa Barat, seperti Sastra Lisan Sunda (1982); Sastra Lisan Jawa tahun tersebar; Kalimantan, seperti Sastra Lisan Banjar (1994). D ata penelitian sebagaimana yang disebutkan di atas penulis anggap mewakili di samping data tertulis yang berupa buku-buku hasil penelitian sebagai dokumen atau pustaka.

\section{LAN DASAN TEORI}

Penelitian ini dilakukan dengan menerapkan prinsip-prinsip strukturalisme dan fungsionalisme dalam kajian mantra. Jean Peager (1978) dalam bukunya Strukturalisme and Semictics menyatakan bahwa pengertian struktur dapat dipahami lewat susunan keseluruhan, meliputi tiga gagasan fundamental yang mencakup ide keutuhan (the idka of wholemess), ide transformasi (the idea of transformation), dan ide adanya aturan sendiri (theidka of seff-regulation).
Adapun yang dimaksud dengan keutuhan ialah koherensi internal. Susunan dari suatu keutuhan lengkap dengan sendirinya dan bukan merupakan gabungan yang dibentuk oleh elemenelemen independen yang berbeda-beda. Bagianbagian unsurnya membentuk seperangkat aturan instrinsik yang menentukan hakikatnya. Aturan instrinsik ini lebih banyak menjadikan bagianbagian unsur memiliki sifat-sifat keseluruhan struktur daripada sifat-sifat individual yang dimilikinya di luar struktur. D emikianlah sebuah struktur sangat berbeda dan suatu himpunan (aggegate) karena bagian-bagian unsurnya tidak memiliki eksistensi yang independen di luar struktur.

Struktur itu memiliki aturan sendiri, dalam arti bahwa struktur tidak menunjuk pada pertimbangan-pertimbangan di luar dirinya dalam rangka mengesahkan prosedur transformasionalnya. D emikianlah gagasan mengenai struktur merupakan dasar bagi suatu hukum yang mandiri (safsufficent rules) (Hawkes, 1978 dalam Soedjijono, 1987). G agasan struktur merupakan suatu konstruksi konkret, yang bagian-bagiannya sanggup mengubah dimensi dan kualitasnya, dan tidak ada bagian dari keseluruhan yang dapat dihilangkan tanpa merusak keutuhannya. Semua bagian dari suatu struktur secara potensial efektif. Fungsi dari beraneka ragam bagian struktur tergantung pada konteks dan perangkat struktur (Fokkema dan Kunne-Ibach, 1977: 21-22). D engan demikian, gagasan struktur semua bagian atau unsur verbal yang membangun keutuhan komposisi mantra memiliki fungsi sesuai dengan konteknya sehingga efektif dalam mewujudkan ciri estetika pengungkapan mantra.

Tentang isi mantra, pengkajian tentang sastra dengan metode dikdomi memisahkan karya sastra menjadi dua bagian, yaitu bentuk dan isi. Rene Wellek dan Austin Warren dalam bukunya Theary of Literature (1976) menyatakan bahwa jika kita 
menganggap isi adalah ide-ide atau emosi yang diungkapkan isi (Wellek dan Warren, 1976: 140). Mereka menyadari bahwa pembagian secara tegas dalam bentuk dan isi mengandung banyak keberatan. Masalahnya adalah antara bentuk dan isi dapat diakhiri. Struktur adalah suatu konsep yang memasukkan, baik isi maupun bentuk sejauh keduanya diorganisasikan untuk tujuan estetik (Wellek dan Warren, 1976: 141). Namun, tanpa mengurangi kecurigaan Wellek dan Warren atas pembagian bentuk dan isi, dimaksudkan sebagai makna yang dibangkitkan oleh bunyi, kata, frasa, kalimat, bahkan keseluruhan wujud komposisi verbal mantra.

Berbagai macam makna yang dapat diungkapkan lewat elemen-elemen linguistik yang digunakan dalam mantra, di antaranya adalah makna denotatif, emotif, dan kognitif. Makna denotatif berkaitan dengan definisi kamus atau dapat juga sebagai makna kata yang wajar dan konkret, yang bebas dari segala makna tautan atau pun nilai rasa (Keraf, 2008: 54). Makna konotatif adalah makna yang timbul dari sugesti dan asosiasi. Makna emotif merupakan muatan emosi yang dirasakan timbul sebagai akibat dari konotasi kata. Makna kognitif disebut juga makna referensial atau deskriptif, yaitu makna yang menegaskan, menonjolkan, atau mengutamakan realitas. Pertanyaan kognitif tidak mengungkapkan sikap atau emosi pembicara dan karena itu merupakan lawan dari makna emotif.

Di dalam mantra; makna denotatif, konotatif, emotif, dan kognitif dapat dijumpai, tentu saja tidak dikaitkan dengan individualitas pengarang karena mantra bersifat anonim dan merupakan warisan yang turun-temurun. Referensi mantra menunjuk pada sistem kepercayaan, religi, dan dunia gaib. Hal tersebut menunjukkan bahwa eksistensi mantra hanya dapat dipahami secara lengkap dengan mengembalikannya pada kenyataan, emosi, dan asosiasi yang tumbuh dari penghayatan dan pengalaman dunia spiritual dan magis itu.

\section{PEMBAHASAN}

\subsection{Bentuk dan Fungsi Mantra}

Pengkajian bentuk dan di dalamnya isi dengan metode dikotomi memisahkan karya sastra menjadi dua bagian, yaitu bentuk dan isi. Rene Wellek dan Austin Warren dalam bukunya Theary of Lite rature (1976) menyatakan bahwa jika kita menganggap isi adalah ide-ide atau emosi yang diungkapkan bentuk sastra, sedangkan bentuk adalah semua elemen linguistik yang mengungkapkan isi (Wellek dan Warren, 1976: 140). Mereka menyadari bahwa pembagian secara tegas dalam bentuk dan isi tidak dapat ditarik garis yang tegas. D engan mengambil konsep struktur; pembedaan antara bentuk dan isi dapat diakhiri. Isi atau bentuk dalam konsep struktur diorganisasikan untuk tujuan estetis (Wellek dan Werren, 1976: 141).

Terlepas oleh kecurigaan mereka atas pembagian bentuk dan isi dalam penelitian ini, isi dimaksudkan sebagai makna yang dibangkitkan oleh bunyi, kata, irama, kalimat, bahkan terjadi dari ke seluruhan wujud komposisi verbal mantra. Mantra dapat digolongkan menjadi beberapa bentuk, antara lain: (1) mantra bentuk pantun, (2) mantra bentuk puisi, (3) mantra bentuk prosa lirik, (4) mantra bentuk pengulangan bunyi, dan (5) mantra bentuk kidung.

\subsubsection{Mantra Bentuk Pantun}

Pantun adalah jenis puisi lama yang terdiri atas empat larik bersajak silang a-b-a-b; tiap larik biasanya berjumlah empat kata. D ua larik pertama yang lazim disebut sampran menjadi petunjuk nima; dua larik berikutnya yang mengandung inti artinya; disebut isi pantun. Ada juga pantunyang terjadi dari enam atau delapan lanik (taliban). Menilik ragam isinya pantun dibedakan menjadi: pantun kanakkanak, pantunadat, pantun agama, pantun teka-teki, dan sebagainya (Sudjiman, 1984: 55). Perhatikan contoh mantra bentuk pantun berikut. 
(1) Bismillaahirrahmaanirrahim

Minyak si tuangtuang

dituang dalam kuali

bukan aku togak surang

sarato bulan jo matcari

(Sastra Lisan Minangkabau, 1981: 119)

Bismillahirrahmanirrahim

Minyakku si tuang-tuang

dituang dalam kuali

bukan aku tegak seorang

beserta bulan dengan matahari

Mantra bentuk pantun empat larik bersajak a-b-a-b- (1) berkaitan dengan minyak Sinyonyong yang berfungsi untuk mengasihi seorang gadis atau mantra berkasihan. Selanjutnya, perhatikan contoh pantun yang terdiri atas delapan larik berikut.

(2) Bimillahirahmanirrahim

Ada angin kada angin

Ada guntur kada guntur

Ada langit kada langit

Ada awan kada awan

Hayu naik ka awan-awan

Cinkki walaikala

Ada nang wani

Ada angin Sir Allah

Sir angin sir Muhammad

Barakat La ilahaillah

(Sastra Lisan Banjar,1996:38)

D engan nama Allah Yang Maha Pengasih lagi

Maha Penyayang

Ada angin tidak angin

Ada guntur tidak guntur

Ada langit tidak langit

Ada awan tidak awan

Ayo naik ke awan-awan

Tidaklah kalau mau
Ada yang berani

Ada angin milik Allah

Ayo angin dipegang Muhammad sebagai musim Allah

Berkat tiada Tuhan, melainkan Allah Muhammad utusan Allah

Mantra di atas terdiri atas delapan larik, yang berfungsi untuk mengalahkan lawan dalam permainan layang-layang ini dalam bahasa Banjar disebut "Main Kaleyangan" (dalam bahasa Indonesia 'Main layang-layang').

\subsubsection{Mantra Bentuk Puisi}

Jenis mantra berbentuk puisi adalah ragam sastra yang bahasanya terikat oleh irama, matra, nima, serta penyusunan larik dan bait (Sudjijono, 1984:61), sedangkan pengulangan dapat diterapkan bunyi, suku kata, frasa, bait, pola matra, gagasan, kilatan, dan bentuk (Sudjiman, 1984:78). Pengulangan merupakan unsur penyatu yang sangat penting hampir semua ragam puisi. Tutur dalam puisi sering diulang-ulang. Mantrajenis puisi karena bentuknya yang tetap dan bersajak. Puisi mantra adalah puisi yang mengikuti pola mantra; yang dipopulerkan oleh Sutardji Calzoum Bachri. Perhatikan contoh jenis mantra bentuk puisi atau puisi mantra berikut.

(3) SEPI SAUPI

sqpisau luka spisau dun

sqpikul dbsa sepukau sqi

sqpisau duku squisau din

sqpisau sepi spisau nyanji

sepisaupa sepisaupi

sepisapanya sepikau spi

sepisaupa sepisaupi

sepikul dari keranjang duri

sepisaupa sepisaupi

sepisaup sepisaupi 
sepisaupa sepisaupi

sampai pisaunyaNya ke dalam nyanyi

(Sutardji Calzoum Bachri dalam Eddy, Nyoman

Tusthi, 1991: 177)

(4) Roh man, rahan man,

Semangat man, marilah engkau semanya.

Mari jangan engkau jauh semangat,

Teegr besi, teegr semangat,

Jangan kau singgah d numah tangga arang

Jangan kau singgah di bulan,

Jancan kau singgeh di lautan

Jangen kau singgeh d kayu besar.

Jancan kau singcgh di tempat perjunu

Teap kau tinggel di anggotaku

(Sastra Lisan Melayu Timur, 1992: 23)

Mantra (4) ini dibaca agar berlagu dengan bunyi yang lirih, pengulangan kata-kata puisi mantra tersebut dapat kita lihat pengulangan kara man sebanyak 5 kali, engkau 2 kali, semangat 4 kali, kata jangan 7 kali, kausebanyak 8 kali, dan singgah 5 kali. D i samping pengulangan kata depan menandai tempat seperti di rumah, di hutan, di kayu, d anggotaku. Bunyi vokal a semuanya, orang, lautan, besar, upada semangatku, tujuh, daku, penjuru anggotaku

\subsubsection{Mantra Bentuk Prosa Linik}

Prosa lirik adalah karya sastra yang ditulis dalam ragam prosa, tetapi dicirikan oleh unsur-unsur puisi, seperti irama yang teratur, majas, rima, asonansi, konsonansi, dan citraan (Sudjiman, 1984: 61). Nyoman Tusthi Eddy (1991:168) menyatakan bahwa prosa lirik adalah karya sastra yang ditulis dalam bentuk prosa, tetapi sangat kaya dengan unsur-unsur puisi, terutama ritme (irama) dan diksi (gaya ucap). Ia membedakan dua macam lirik, yaitu prosa lirik yang diadaptasi dari kesastraan klasik dan prosa lirik modern. Perbedaan antara prosa lirik dan prosa lirik modern terletak pada tata korespondensinya (lirik modern) yang keprosaannya memiliki gaya ungkapan yang bebas.

Kita ketahui bahwa lirik dalam sastra Yunani adalah sebuah syair yang diiringi dengan petikan alat lira. Lirik secara spontan melahirkan dan mewujudkan perasaan batin seseorang. Sifat-sifat liriknya mengutamakan nada dan irama, abstraksi terhadap waktu dan tempat tertentu, serta gaya yang langsung menyapa perasaan pembaca atau pendengar.

Pada tulisan ini dicontohkan tentang mantra bentuk prosa lirik dari Sastra Lisan Banjar(Sunarti, et al., 1996:72). Ceritanya di sebuah desa tinggal seorang janda miskin berputra seekor ikan Baung (jenis ikan air tawar). Si Baung ingin melamar putri raja. Raja bertransaksi mau menerima si Baung asalkan syarat yang beliau (Raja) minta dipenuhi. Dengan berbekal mantra, lamaran si Baung diterima oleh Raja.

Dalam mantra tersebut; Yang Maha Kuasa mengabulkan si Baung. Permintaan emas dan uang langsung sampai di rumahnya. Uang kemudian disampaikan kepada raja sehingga perkawinan ditetapkan, dan Si Baung dikawinkan dengan anak raja. Bentuk mantranya tampak berikut.

(5) Riangriang ari pukulun

Riangriang ari bajangga

Asal aku anak raja, asal aku anak ratu

Aku ini hendak babini

Dipinta pengkatrya amas sabaki

Mun pacah niak d muntung

Mun pacah niak di bibir

Sudah ada amas sadipir

Sudah ada diit segantang

(Sastra Lisan Banjar, 1976: 72)

Riang-riang ari pakulun

Riang-riang ari bujangga

Asal aku anak raja, asal aku anak ratu

Aku ini hendak berbini 
D iminta pengikatnya emas sebaki

Lamun pecah riak di mulut

Lamun pecah riak di bibir

Sudah ada emas sebaki

Sudah ada duit sepantang

Selanjutnya, contoh lain dalam mantra bentuk prosa lirik yang mengisahkan tentang Nini Yaksa sebagai berikut. Pada zaman dahulu ada dua orang anak raja yang dibuang di hutan. Kedua orang anak raja itu disingkirkan oleh pamannya yang merebut tahta raja ayahnya, sedangkan anak raja itu yang tua laki-laki bernama si Utuh dan adiknya perempuan bernama si Galuh. Nini Yaksa ingin makan hati anak itu. Setiap Nini Yaksa datang, si Galuh mengatakan bahwa hatinya masih kecil. Lain hari Nini Yaksa datang lagi dan si G aluh ditangkap dan dimakan. Si Utuh kakaknya marah ingin menghidupkan lagi si $\mathrm{G}$ aluh dengan melecutkan lidi daun kelapa gading. Adiknya ditutup kain putih dan si Utuh mengucapkan mantra seperti berikut.

(6) Pat kupati, babadan adingku cara milanya Pat kupati, babatis batangan adingku cara milanya Pat kupati, bakapala, bamata, bahidung bakaning babuntung

adingku cara nulanya

Pat kupati, bahinak adingku cara milanya

(Sastra Lisan Banjar, 1976: 55)

'D engan mengucapkan kepada Tuhan Yang Mahakuasa; kembalilah seperti semula: Kami mohon agar; berkepala, bermata, berhidung, berkening, bermulut, mohon kami agar adikku dapat berbicara seperti semula.'

D engan demikian, sesudah dibacakan mantra oleh si Utuh, adiknya yang bernamasi $\mathrm{G}$ aluh hidup kembali seperti sediakala. Kemudian si G aluh menceritakan kejadiannya kepada kakaknya. Selanjut- nya, mereka berencana akan membalas dendam terhadap Nini Yaksa.

Mantra dalam prosa lirik bagi seorang pengarang nod atau cerita pendek, yaitu untuk memperkaya seorang pengarang cerpen atau novel, seperti irama, simbolik bunyi, metafora, itu tidak lain adalah untuk menyampaikan perasaan batin pengarang.

\subsubsection{Bentuk Puisi Mantra Pengulangan Bunyi}

Puisi adalah ragam sastra yang bahasanya terikat oleh irama, matra, serta penyusunan larik dan bait (Sudjiman, 1984: 61), sedangkan pengulangan (Sudjiman, 1984: 78) dapat diterapkan pada bunyi, suku kata, kata, frasa, bait, pola matra, gagasan, kilatan, dan bentuk. Ulangan dapat juga terjadi pada referen, asonansi, rima, purwakanti, dan tiruan bunyi. Pengulangan merupakan unsur penyatu yang sangat penting di dalam hampir semua ragam puisi dan prosa, sedangkan prosa adalah ragam sastra yang dibedakan dengan puisi karena tidak terlalu terikat oleh irama, rima, dan kemerduan bunyi (Sudjiman, 1984: 60; Dick Hartoko dan Rahmanto, 1998: 111). Tutur (kata) dalam puisi sering diulang-ulang, tetapi membujur. Oleh karena itu, dalam sastra modern perbedaan antara puisi dan prosa sering kabur. Perhatikan bentuk puisi mantra pengulangan bunyi dalam Mantra Melayu Sumatra Timur berikut.

(7) Roh mani, rahan man,

Semangat man, mailah engkau semanya.

Mani, jangan engkau jauh semangat,

Tegar besi, teegar semangatku

Pulangkau semangat tujuh ketujuh

Jangan kau perg dari daku

Jangan kau singgah di numah tangga arang

Jangan kau singgah d hutan

Jangen kau singghh di lautan

Jangan kau singgah di kayu besar. 
Jangan kau singegh di tempat perjunu

Tetap kau tinggel di anggdaku

(Sastra Lisan Banjar, 1976)

Mantra di atas dibaca agar berlagu dengan bunyi yang pelan-pelan, merdu. Pengulangan katakata puisi mantra tersebut dapat diperhatikan pengulangan kata main 5 kali, engkau 2 kali, semangat 4 kali, kata jangan 7 kali, kau 8 kali, singogh 5 kali, dan sebagainya. Di samping pengulangan kata depan di yang menandai tempat seperti di numbh di hitan di lautan di kayu di anggotaku Bunyi vokal a semuanya, orang, lautan, besar, u semangatku, tujuh, daku penjuru anggotaku

Kata-kata atau ayat yang dibaca oleh dukun atau pawang, mantra itu dapat menimbulkan kuasa gaib; kata-kata dianggap berisi kesaktian atau kekuatan mengutuk. Hal itu terjadi karena mantra yang semula berisi semangat "hilang" sesudah dimantrai dalam atau oleh waktu yang singkat dan akan pulih (sembuh) bagi si sakit.

\subsubsection{Mantra Bentuk Kidung}

Kidung ialah nyanyian, lagu atau syair yang dinyanyikan, disebut jugapuisi Jawa (tembang Jawa; atau sanjak Kams Besar Bahasa Indonesia (KBBI, 2014:510). Menurut Zoetmulder dalam bukunya Kalangran Sastra Java Kum Sdayang Pandang (1984: 142) menjelaskan bahwa kidung adalah sejenis puisi Jawa Pertengahan yang mempergunakan metrum-metrum asli Jawa. Metrum kidung disebut metrum tengahan dan prinsip dasarnya sama dengan metrum dalam puisi Jawa modern yang dinamakan macapat. Kidung memiliki ciri-ciri sebagai berikut. 2) Jumlah baris dalam satu bait tetap sama selama metrumnya tidak diganti. Keanekaan terjadi karena metrum tertentu yang dipakai. Semua metrum tengahan mempunyai lebih dari empat baris, berlainan dengan kakawin. 2) Jumlah suku kata dalam setiap baris tetap, tetapi panjang baris itu dapat berubah menurut kedudukannya dalam bait. 3) Sifat sebuah vokal dalam suku kata yang menutup setiap baris juga ditentukan oleh metrum. Dengan demikian, persajakan dalam kidung memperlihatkan semacam rima yang sama sekali tidak dikenal dalam metrum di India. Berikut contoh mantra Kidung tembang macapat (tambang cilik), penolak bala, setan, dhemit, dan sebagainya dengan tembang Asmaradana berikut.

(8) Aja turu sareKaki 8 (i) Ana dava ngangangjagad 8 (a)

Nyangkingbokor kencaname8 (e)

Isinedonga teddak 8 (a)

Sandhang kalawan pangan 7 (a)

Yaiku bagganipun 8 (u)

Wongmidk sabar naima 8 (a)

'Janganlah tidur (masih) sore Kaki, ada dewa mengelilingi jagad, membawa bokor emas kuningan, isinya mantra penolak bala, pakaian dan makanan, yaitu pembagiannya, orang selalu terjaga sabar menerima (pembagiannya)'

Kidung cengkok tembang Asmaradana itu ditembangkan oleh nenek kita sejak zaman dahulu untuk uran-uran yang berfungsi untuk menolak bala. Sekarang setiap ada acara macapatan masih dialunkan. D alam Wilujengan Nagari dan Ruwatan oleh paranormal di Surakarta pada Minggu 18 Agustus 2002, yaitu Ruwatan Anak Nagari Padhepokan Bumi Langit gelar ruwatan Nagari dibuka dengan mantra penolak bala.

\subsection{Fungsi Mantra dalam Masyarakat}

Fungsi mantra berkaitan dengan jenis mantra, yakni fungsi sosial. Fungsi sosial mantra adalah kegunaan mantra itu bagi kehidupan dalam masyarakat setempat. Mantra itu banyak jenisnya dan setiap jenis mantra mempunyai fungsi (kegunaan) atau khasiat (manfaat). K hasiat adalah faedah yang bersifat khas; kekuatan (kegunaan, faedah) yang 
istimewa tentang obat, azimat, dan sebagainya. Khasiat atau manfaat itulah yang disebut fungsi mantra. D alam makalah ini, mantra secara umum berfungsi (1) untuk kekeluargaan, (2) untuk pengobatan, (3) untuk membasmi hama, (4) untuk kekebalan, (5) untuk permainan, (6) untuk kesehatan, (7) untuk cinta kasih (percintaan), (8) untuk menjinakkan harimau, (9) untuk mata pencaharian, dan sebagainya.

\subsubsection{Fungsi Mantra untuk Kekeluargaan}

Kekeluargaan adalah perihal yang bersifat, berciri keluarga. Keluarga ibu bapak dengan anakanaknya, seisi rumah. Keluarga orang seisi rumah yang menjadi tanggungan, batih, bahkan keluarga sanak saudara, dan kaum kerabat. Mantra sakit hendak melahirkan atau beranak. Berikut adalah contohnya.

(9) Bismillahirahmanirrahim

Nun kalamm walayar tunun

Insya Allah inya ilang ingatan

Inya turun

Barakat La ilahailallah

Muhammadarasulallah

(Sastra Lisan Banjar, 1966: 28)

D engan nama Allah Tuhan Yang Maha Pengasih lagi Maha Penyayang

Tuhan yang mengetahui sebenarnya

D emi pena apa yang mereka tuliskan

Kalau diizinkan Allah ia hilang rasa sakit Ia turun

Berkat tiada Tuhan, melainkan Allah

Muhammad pesuruh Allah

Fungsi mantra (9) agar seorang ibu atau calon ibu mudah atau cepat melahirkan tidak merasa sakit. Insyaallah bayi yang dilahirkan selamat sesuai keinginan sang ibu atau keluarga.
Mantra itu dibaca oleh bidan yang membantu melahirkan. Tugas bidan mengawasi dan memberi nasihat kepada sang ibu atau calon ibu selama mengandung sang bayi. Ini penting karena pengawasan atau nasihat selama usia hamil perlu perhatian sungguh.

\subsubsection{Fungsi Mantra untuk Pengobatan}

Mantra yang berkaitan dengan pengobatan sangat banyak dan bervariasi, misalnya untuk mengobati penyakit panas, sakit syaraf, sakit gigi, sakit bengkak, sakit kepala, masuk angin, dan sebagainya. Perhatikan contoh berikut.

\section{(10) Tut dan dalih}

\section{Buangketht}

tinggel tahi

Barakat La ilaha ilallah

Muhammadararasulallah

(Sastra Lisan Banjar, 1996: 54)

Bunyi kentut yang keluar dari dubur

Membuang kentut

tinggal tahi

Berkat tiada Tuhan, melainkan Allah

Muhammad pesuruh Allah

\subsubsection{Fungsi Mantra untuk Membasmi Hama}

Jenis hama itu bermacam-macam, yaitu hama ulat buku, hama tanaman umbi-umbian, hama perusak tanaman padi, dan sebagainya. Mantra dalam bahasa Melayu Sumende, Bengkulu disebut jami. Mantra atau jampi merupakan puisi yang berisi perkataan atau kalimat yang memiliki kekuatan gaib. Kekuatan gaib yang ditimbulkan oleh mantra ini merupakan permainan bunyi dalam kata yang digunakan oleh kata-kata itu yang tidak diketahui secara jelas artinya. Bandingkan dengan puisi mantra Sutardji Calzoum Backri pada subbab 4.3 nomor (3). Perhatikan contoh fungsi mantra untuk membasmi hama ulat buku atau ruas-ruas batang padi berikut. 
(11) Allahumma shalli ala

Sayjidima Muhammad

Huu

Aku tau asal ulat

Ulat gading ulat semiling

Jancan engkau menabemenjikse

Kalau engkau mencoba menjikse

Engkau dhukum Tuhanku

Subhanallah

(Sastra Lisan Sumende, 2000:37)

'Allahumma shalli ala

sayyidina Muhammad

Huu

A ku tahu asal ulat

Ulat gading, ulat semuling

Jangan engkau mencoba menyiksa

Jika engkau mencoba menyiksa

Engkau dihukum Tuhanku

Subhanallah'

\subsubsection{Fungsi Mantra untuk Kekebalan}

Kekebalan adalah keadaan sifat atau hal kebal, daya tahan. Kebal adalah tidak mempan senjata; tidak dapat terlukai oleh senjata; 2 tidak dapat terkena sakit; tahan terhadap penyakit. Mantra untuk kekebalan, yakni mengebalkan dari segala tusukan senjata tajam, tamparan keras atau berat, untuk menghilang, bahkan kekebalan dari gigitan ular, sengatan lebah, kebal untuk melemahkan banteng, dan sebagainya. Perhatikan contoh berikut.

(12) Bismillahirahmanirrahim

Naga ulit naga umbang

Taghh ka kulit sampai ka tulang

Barakat La ilahailallah

Muhammadarasulullah

(Sastra Lisan Banjar, 1996: 126)
Dengan nama Allah Tuhan Yang Maha

Pengasih lagi Maha Penyayang

Naga yang gigih

Kebal dari kulit sampai ke tulang

Berkat tiada Tuhan, melainkan Allah

Muhammad pesuruh Allah

Fungsi mantra (12) di atas adalah untuk menghindarkan diri dari luka atau tembus dari tusukan atau bahkan tembakan senjata api. Perlu diketahui bahwa dalam kehidupan masyarakat Banjar ketahanan diri dari senjata memang sangat diminati di kalangan generasi muda. Hal itu perlu diketahui bahwa para leluhur masyarakat Banjar, tahan diri terhadap senjata hanya untuk keperluan keadaan terdesak atau terjepit. D alam bahasa Banjar "Aggr Tagih lavan Senjata".

\subsubsection{Fungsi Mantra untuk Permainan}

Permainan mengadu jangkrik adalah permainan anak-anak, baik yang tinggal di desa atau di kota. Permainan Jangrik umumnya dilakukan pada musim hujan menjelang musim panas. Pada musim hujan rumput tumuh subur sehingga jangkrik hidup dengan makan rumput. Jangkrik sering juga makan cabai rawit yang pedas. Jangkrik jantan yang akan diadu diberi makan cabai supaya berani dan perkasa. Fungsi mantra mengadu jangkrik adalah sebagai berikut.

(13) Mang gulimanglimang

Undang galah undang sapit

Amn mamang aku timang

Amm kalah aku piak

(Sastra Lisan Banjar, 1996: 43)

Mang kutimang-timang

Udang besar udang dara

Kalau menang aku timang

Kalau kalah aku pencet 
Mantra (13) di atas diucapkan tiga kali sambil menimang. Setelah dibacakan mantra jangkrik semakin hebat berani. Umumnya mantra ini dibaca sambil menimang-nimang jangkrik, dan jangkrik yang ditimang-timang mampu berkelai selama beberapa menit. Sebaliknya, jangkrik lawan yang tidak ditimang-timang akan loyo dan lari ketakutan.

\subsubsection{Fungsi Mantra untuk Kesehatan}

Fungsi atau jenis mantra untuk kesehatan yaitu untuk mengobati sakit perut. Perlu diketahui bahwa masyarakat tradisional pada waktu itu belum ada balai pengobatan atau Puskesmas seperti zaman sekarang. Perhatikan contoh mantra untuk mengobati sakit perut.

\section{(14) Bismillahirrahmminrahim}

Bakaliha ka bakalaillaika

sama kuuma kahakalika

peduatan deso sakalian

kumbali kepada deso

dikembalikan Allah

dikembalikan Muhammad

barckat Laailaahaillah

(bacaan zikiz lima puluh kali)

(Sastra Lisan Minangkabau, 19981: 135)

Bismillahirrahmanirrahim

Bakaliha ka kakaliha

sama kunna kabaliha

perbuatan deso sekalian

kembali kepada deso

dikembalikan Allah

dikembalikan Muhammad

berkat Laailaahailallah

(bacaan zikir lima puluh kali)

\subsubsection{Fungsi Mantra untuk Cinta Kasih (Mantra Pengasihan)}

Dalam pergaulan muda-mudi akan menumbuhkan saling cinta kasih. Cinta kasih sering terjadi melalui baca mantra terutama laki-laki terhadap perempuan. Adapun mantra tampak sebagai berikut.

(15) Sirku simu

Inilah kanasehan yang seningking skali

Kur Semangaine

Ati (s anu yangdituju)

(Sastra Lisan O gan, 1984: 16)

Sirku sirmu

Inilah mantra yang paling mujarab

Kur semangatnya

Hati (si anu gadis/ laki-laki)

Mantra untuk cinta kasih umumnya menggunakan makanan, minuman, dan rokok. Hal ini dilakukan hampir di seluruh wilayah Nusantara.

\subsubsection{Fungsi Mantra untuk Menjinakkan H arimau}

Masyarakat kita masih banyak yang menjinakkan binatang buas, salah satunya harimau dengan mengucapkan mantra. Adapun mantranya tampak sebagai berikut.

(15) Bismillahirahmanirrahim

Sima ula sima maung

sinungkemsima manusa

cep bungkemroh bungkem

(Sastra Lisan Sunda, 1978: 91)

Bismillahirrahmanirrahim

harimau ular harimau macan

dibungkam harimau oleh manusia

diam bungkam roh bungkam 
Mantra di atas berfungsi untuk menjinakkan harimau (macan) supaya harimau menjadi jinak dan tidak menyerang orang.

\subsubsection{Fungsi Mantra Berkaitan dengan Mata Pencaharian}

Mantra yang berfungsi untuk mata pencaharian adalah pekerjaan atau pencaharian utama (yang dikerjakan untuk biaya sehari-hari), seperti pertanian, perkebunan, dan sebagainya. Mantra berfungsi untuk melebatkan buah pisang. Selain buah rambutan, buah pisang juga merupakan buah yang sangat disukai oleh masyarakat Banjar. Adapun mantra untuk melebatkan buah pisang (bahasa Banjar: "Malabatakan Buah Pisang") adalah sebagai berikut.

\section{(17) Bismillahirahnirrahim \\ Uma ditanam \\ Anak dihambin \\ Barakat La ilahailallah \\ Muhammadarasulullah}

D engan nama Allah Tuhan Yang Maha

Pengasih lagi Maha Penyayang

Induk ditanam

Anak berbuah tumbuh berlimpah

Berkat tiadaTuhan, melainkan Allah

Muhammad pesuruh Allah

Fungsi mantra di atas agar pohon pisang yang ditanam menghasilkan buah yang banyak, melimpah, dan berisi sehingga produksi buah pisang meningkat. (Sastra Lisan Banjar, hlm.142)

\section{SIMPULAN}

Mantra berdasarkan bentuknya dapat ditemukan, antara lain mantra bentuk pantun, mantra bentuk puisi, mantra bentuk prosa lirik, mantra bentuk pengulangan bunyi, dan mantra bentuk kidung. Fungsi mantra sangat bervariasi berdasar- kan wilayah persebarannya. Fungsi mantraitu, antara lain, (1) mantra untuk kekeluargaan, (2) mantra untuk pengobatan, (3) mantra untuk membasmi hama, (4) mantra untuk kekebalan, (5) mantra untuk permainan, (6) mantra untuk kesehatan, (7) mantra untuk cinta kasih (berkasih-kasihan), (8) mantra untuk mata pencaharian, dan sebagainya.

\section{DAFTAR PUSTAKA}

Alisjahbana, Takdir, S. 1975. Puisi Lama Jakarta: Dian Rakyat.

Bakar, Jamil, dkk. 1981. Sastra Lisan Minangkabau, Pepatah, Pantun, dan Mantra. Jakarta: Pusat Pembinaan dan Pengembangan Bahasa, Depdikbud.

Calzoum Bachri, Sutardji. 1998. "Air Mata Setelah Mantra", dalam Majalah G atra, Jakarta. Tanggal 28 Maret 1998, hlm.60.

Eddy, Nyoman Tusthi. 1991. Kamus Istilah Sastra Indonesia. Ende-Flores: Nusa Indah.

Fachruddin A.E., dkk. 1981. Sastra Lisan Bugis Jakarta: D epartemen Pendidikan dan Kebudayaan, Pusat Bahasa.

Hartoko, Dick dan Rahmanto. 1998. Kams Istilah Sastra. Yogyakrta: Kanisius.

Ismali, Abdulrachman, dkk. 1996. Mantra dalam Masyarakat Banjar. Jakarta: D epartemen Pendidikan dan Kebudayaan, Pusat Pembinaan dan Pengembangan Bahasa.

Kamus Besar Bahasa Indonesia (K BBI), 2014.

Departemen Pendidikan dan Kebudayaan.

Jakarta: Balai Pustaka.

Kemp, Gillian. 2002. Kitab Mantra: Daya Tarik

Cinta, Penyenbuhan Magis dan Praktdk Sihir lainnya Jakarta: Penerbit Abdi Tandur.

Sudjiman, Panuti. 1984. Kamus Istilah Sastra. Jakarta: G ramedia.

Tansin, Medan. 1975. "Mantra dalam Kesusastraan Minangkau". Dalam Bahasa dan Sastra 
Tahun I, No. 2. Penerbit Angkasa Raya Padang 1988.

Wellek, Rene, dan Austin Warren. 1976. Theary of Literature New York: Harcourt, Bruce \& World.Inc.

Z oetmulder, P.J. 1983. Kalangnan Sastra Jana Kumo SdayangPandang (Terjemakan D ick Hartoko). Jakarta: Djambatan. 
